\title{
EVOLUSI IDENTITAS BRAND DI TENGAH ARUS GLOBALISASI
}

\author{
Ina Nur Ratriyana \\ Program Studi Ilmu Komunikasi, Universitas Atma Jaya Yogyakarta \\ Email: ina_nur@staff.uajy.ac.id
}

\begin{abstract}
ABSTRAK
Dalam konteks komunikasi, globalisasi bisa kita pahami sebagai sebuah relasi sosial dalam sebuah kesatuan ruang dan waktu. Ada dua kubu berbeda dalam memahami globalisasi dan pengaruhnya pada identitas yakni, pertama, kubu yang berfikir globalisasi sebagai sesuatu yang positif karena mampu membentuk identitas brand yang bersifat global dengan tetap membawa keyakinan dan nilai budaya lokal di tingkat dunia. Kedua, pihak yang melihat globalisasi sebagai sesuatu yang negatif dan menganggap globalisasi sebagai ancaman identitas. Dengan menggunakan metode literature review, tulisan ini mencoba menggali fenomena evolusi identitas brand di tengah nilai global dan lokal. Berdasar pada Teori Imperialisme Budaya (cultural imperialism theory) terdapat penegasan bahwa sistem ekonomi global didominasi oleh negara maju. Sebuah brand harus memiliki identitas yang kuat dalam membangun positioningnya di tengah pasar global dengan unique value menjadi modal utama untuk bersaing sehingga mampu memenangkan pasar. Di tengah maraknya perdebatan mengenai globalisasi kemudian muncul konsep project identity dan hybrid brand dan menegaskan bahwa sebenarnya brand lokal bisa bangkit dan bersaing dengan produk global.
\end{abstract}

Kata kunci: Komunikasi, globalisasi, budaya, identitas, brand, positioning, hybrid brand.

\begin{abstract}
In the context of communication, we understand globalization as social relation which assimilate in the unity of time and place. There are two different perspectives about globalization and its impact into identity. The first perspective understands globalization as something positive because its ability to shape the global brand identity while bring the believe and local value in the global level. On the other side, the second perspective see globalization as a threat of local identity and should be avoided. This paper use literature review to portrait identity evolution phenomenon in the middle of global era. In addition, the cultural imperialism theory strengthen the premise of global economic system which dominated by big-western countries. As foundation, if a brand have strong identity and unique value for building its positioning, surely it can win the market. Surprisingly, in the middle of the debate about globalization, some people initiate project identity and hybrid brand which show that local brand has its power to compete in the middle of the globalization chaos.
\end{abstract}

Keywords: Communication, globalization, culture, identity, brand, positioning, hybrid brand.

\section{PENDAhUluan}

Globalisasi menjadi sebuah arus yang tidak bisa lagi dihindari. Perdebatan mengenai penolakan akan keberadaannya masih saja mewarnai diskusi, terutama dalam hal identitas dan lokalitas. Adanya ketakutan akan keberadaannya sehingga beberapa kelompok memilih menutup diri. Di sisi lain, dalam tataran diskusi komunikasi, globalisasi hadir dengan nyata dalam ranah diskusi brand. Ketika brand global masuk ke pasar lokal, mau tidak mau harus ada sesuatu yang dilakukan apalagi di akhir tahun 2015 telah dicanangkan MEA (Masyarakat Ekonomi Asean) sehingga setiap negara harus siap dengan adanya kemudahan investasi dan invansi produk asing.

Lalu bagaimana brand lokal harus bersikap dan berinovasi dalam menghadapi arus globalisasi?
Menutup diri bukan lagi opsi yang memungkinkan justru pada saat ini tantangan strategi brand semakin berat dan brand lokal harus bisa membuktikan diri, bukan lagi hanya menjadi penonton. Bahkan akan sangat baik apabila pemilik brand lokal mampu berkompetisi di ranah global tidak hanya di negeri sendiri.

\section{MEMAHAMI GLOBALISASI}

Konsep awal globalisasi diperkenalkan oleh Marshall McLuhan ${ }^{1}$ dengan menghubungkan teorinya "the medium is the message" dengan konsep "global village" (Turner \& Khondker, 2010:42). McLuhan memahami globalisasi sebagai perpanjangan jangkau-

\footnotetext{
${ }^{1}$ McLuhan menuliskan pemikirannya mengenai global village dalam tulisannya Understanding Media (1964)
} 
an indera yang melampaui batasan peristiwa hingga sejauh sisi lain tempat di dunia seolah-olah kita pun merasakan fisik kita berasa di sana. Giddens (Turner \& Khondker, 2010:188) juga menambahkan konsep yang kemudian lebih menekankan relasi sosial, tidak hanya melulu masalah tempat atau geografi. Kedua pendapat itupun diperkuat oleh Robertson (Turner \& Khondker, 2 010:39) dengan konsepnya "world as whole" dan Rantanen (2005:8) yang melihat globalisasi sebagai kesatuan dalam berbagai hal. Dalam perspektif komunikasi, globalisasi bisa kita pahami sebagai sebuah relasi sosial yang berada dalam sebuah kesatuan yang tidak bisa dipisahkan oleh ruang dan waktu.

Pada dasarnya, globalisasi dilihat dalam tiga buah pemahaman ataupun kombinasinya (Turner \& Khondker, 2010:17). Pertama, sebagai bentuk unifikasi dunia, mengintegrasikan negara-negara di dunia ini dalam sebuah pasar yang sama. Kedua, globaliasi dipahami sebagai eufimisme dari westernisasi dimana hegemoni barat di dunia ini sebagai sebuah bentuk cultural imperialism. Ketiga, globalisasi mempengaruhi semua aspek dalam hidup termasuk menghapus perbedaan dan menciptakan dunia yang homogen.

Proses globalisasi atau juga disebut sebagai 'modernization of modernity' oleh Giddens ini panjang dan tidak terjadi seketika. Menurut Giddens (Rantanen, 2005:4; Turner \& Khondker, 2010:188), kebanyakan efek globalisasi dirasakan di ranah media, olahraga dan pop culture dengan tiga fase. Fase pertama, ketika orang-orang tidak menyadari eksistensi globalisasi. Pada fase ini kebanyakan orang sedang mengenali pesan yang disampaikan media dan tidak menyadari adanya pertukaran experience atau pengalaman. Orang-orang dengan santai melihat fenomena yang datang dan menganggapnya sebagai sebuah normalitas. Hal ini terjadi ketika sebuah produk hadir di pasaran, masyarakat akan menganggapnya sebuah kenormalan dengan munculnya sebuah produk baru.

Fenomena ini kemudian diikuti dengan fase kedua dimana ternyata globalisasi telah hadir namun orangorang tidak menanyakan mengenai kapan atau bagaimana dia hadir namun justru terpana pada efeknya. Misalnya saja di tahun 2010 saat brand Magnum dari PT Unilever menginvasi pasar ice cream Indonesia dengan gencar dan memperkuat positioningnya sehingga membuat konsumen berlomba-lomba membeli produknya dan mengakibatkan out of stock di banyak toko. Masyarakat tidak menyadari kehadiran Magnum sebelumnya dan bagaimana brand tersebut pelan-pelan menguasai pasar.

Fase yang ketiga adalah ketika masyarakat melihat histeria yang diakibatkan oleh globalisasi, orangorang kemudian bertanya bagaimana menghadapi efek negatif dari globalisasi. Pada kenyatannya, globalisasi ini terjadi seperti membuka keran, sekalinya sudah terbuka dan mengalir airnya, sulit sekali untuk menutup dan membuatnya kering seperti sedia kala. Hal ini ditunjukkan dengan beberapa perusahaan global yang kuat di Asia Tenggara seperti Nestle yang merupakan perusahaan consumer goods dengan 15 ribu orang karyawan di ASEAN. Nestle bahkan mampu menancapkan akarnya di lebih dari 189 negara, 2000 brand dengan 335 ribu karyawan di seluruh dunia (KPMG International, 2015; www. nestle.com). Dengan ribuan brands dan karyawan yang ada, posisi Nestle sangat kuat tidak hanya di Asia, namun juga di dunia dalam persaingan produk consumer goods.

\section{MEDIA DAN TEKHNOLOGI SEBAGAI PERANTARA GLOBALISASI}

Media menjadi salah satu perantara dan sekaligus pendorong kuat tersebarnya globalisasi pada dunia secara luas. Banyak pemikir yang menyatakan bahwa sebenarnya globalisasi tidak akan ada tanpa eksistensi media dan komunikasi (Rantanen, 2005:3). Konsep globalisasi yang menghilangkan batasan tempat dan waktu ini kemudian juga disebut 'shrinking world' atau 'time-space compression' yang kemudian membawa konsep baru mengenai identitas. Perkembangan tekhnologi informasi komunikasi dan juga globalisasi mengurangi ruang yang ada antar orang di belahan dunia dan juga faktanya 'space of flows' menggantikan 'space of places' (Koc, 2006). Dengan adanya perubahan ini, orang di berbagai belahan dunia yang berbeda dapat bersama berbagi pengalaman dalam waktu yang sama hanya saja tidak secara fisik namun virtual. Orang tidak lagi berbagi teritori namun memahami dunia sebagai sebuah 'village'.

Tekhnologi berada di belakang proses internasionalisasi serta globalisasi ekonomi, ilmu dan juga budaya. Desentralisasi informasi dan juga tekhnologi komputer membuat orang berpartisipasi dalam 'global village' serta 'network society' yang merupakan sebuah kondisi interkoneksi ekonomi, sosial, politik dan budaya. Dalam analisis sosiologi dan budaya, media seperti televisi satelit, internet, komputer, handphone 
dan lain sebagianya akan meningkatkan interkoneksi dan juga interaksi sosial (Koc, 2006). Dalam kondisi yang serba cepat dan terkoneksi satu sama lain inilah kemudian brand global dengan mudahnya memasuki pasar lokal. Misalnya saja Lazada, sebuah aplikasi belanja online yang dimiliki oleh Rocket Internet dan berbasis di Berlin hingga akhirnya sangat sukses meraih pasar ASEAN mulai dari tahun 2012. Di sisi lain, Lazada juga memberikan kesempatan pada pemilik brand lokal di ASEAN, seperti Indonesia dan Philipina, untuk menawarkan produknya melalui Lazada. Begitu gencarnya kekuatan Lazada di Asia kemudian menarik Alibaba untuk mengambil alih dominasinya dan membeli saham Lazada senilai US\$1.5 miliar di tahun 2016 (Ardhiati, 2016).

Ketika pasar didominasi oleh pesan global maka yang bisa dilakukan negara atau masyarakat adalah beradaptasi atau menyesuaikan diri di bawah tekanan atau dipaksa untuk beradaptasi (Rantanen, 2005:23). Hingga kini, kebanyakan brand beradaptasi dengan globalisasi untuk bisa bertahan. Survival mode ini tentunya tidak bisa dilakukan secara terus menerus tanpa melakukan apapun. Negara dan masyarakat membutuhkan tindakan untuk bisa menjaga identitasnya tanpa terus tergerus oleh arus globalisasi.

\section{PENGARUH GLOBALISASI PADA IDEN- TITAS BRAND}

Identitas merupakan sesuatu yang membedakan karakter individu pada orang-orang dalam kelompok tertentu (Kaul, 2012) berdasarkan pengenalan pada hal yang familiar misalnya pada etnis, bahasa, agama, sejarah, budaya dan atribut politik pada seseorang atau grup (Koc, 2006). Identitas budaya berfungsi sebagai personality dan simbol mendasar dari eksistensinya (Jan, 2009). Identitas ini yang kemudian akan tercermin dalam sebuah brand. Salah satu contoh adalah Garuda Indonesia dengan nuansa Indonesia sebagai identitas brandnya. Garuda Indonesia menerjemahkan ke-Indonesia-an itu dalam branding, iklan, seragam pramugarinya yang bernuansa batik hingga budaya keramahan awaknya untuk menonjolkan nilai-nilai budaya Indonesia.

Ada pula anggapan bahwa identitas bukanlah sesuatu yang statis namun dinamis dan hal ini akan terus menerus berubah dan bertransformasi seiring dengan perkembangan sejarah, sosial dan budaya seperti halnya globalisasi, modernitas, post kolonialisme dan juga inovasi tekhnologi. Pendapat pertama misalnya diungkapkan oleh David Rothkopf (Moussa, 2013) yang mendukung globalisasi dalam bukunya 'In Praise of Cultural Imperialism " dimana dia menyebutkan homogenisasi yang disebabkan oleh globalisasi merupakan bentuk dari nasionalisme baru dan juga romantisme budaya yang positif. Globalisasi mendukung integrasi dan juga menghilangkan tantangan budaya namun juga dimensi negatif dari budaya itu sendiri dan merupakan tahapan vital dari dunia yang stabil dan lebih baik. Hal ini juga diperkuat oleh pendapat Castle (Kaul,2012) bahwa globalisasi merupakan sebuah modernitas dimana modernitas itu merupakan pertanda akan sebuah identitas.

Globalisasi seringkali disebut sebagai konstruksi, orientasi dan ekspansi global. Globalisasi membentuk identitas yang bersifat global, dimana identitas melebur dalam budaya yang homogen dengan tetap membawa keyakinan dan nilai budaya lokal di tingkat dunia. Sebenarnya, globalisasi juga memiliki peranan untuk mengintegrasikan dan juga di lain pihak memperkuat keunikan budaya lokal (Babran, 2008). Sejalan dengan pendapat tersebut, semakin kuat anggapan bahwa globalisasi tidak bisa diinterpretasikan sebagai kreasi dari budaya global namun lebih pada kesempatan dari berbagai budaya untuk bisa berinteraksi dalam skala yang jauh lebih besar. Misalnya saja produk Samsung keluaran Korea Selatan yang mampu menembus pasar dan budaya internasional dengan kemampuannya membaca karakteristik pasar dan berinteraksi masyarakat yang dinamis. Kini Samsung berada di urutan ke-11 dalam The World's Most Valuable Brands dengan value perusahaan berkisar US\$199.4 triliun (www.Forbes. com).

Lalu pandangan yang kedua dari Maude Barlow (Moussa, 2013) dalam artikel jurnalnya yang berjudul 'The Global Monoculture' dimana menurutnya banyak masyarakat, terutama masyarakat asli, melihat budaya sebagai peninggalan mereka yang paling berharga sehingga tanpa hal itu mereka akan kehilangan akar, sejarah dan juga jiwa. Walaupun McLuhan selama ini cenderung mengamini bahwa globalisasi merupakan dampak dari perkembangan sistem komunikasi namun banyak pihak yang tidak

\footnotetext{
${ }^{2}$ Buku ini diawali oleh pemikiran tentang cultural imperialism oleh Herbert Schiller (1976). Schiller dalam tulisannya yang berjudul Communication and Cultural Domination melihat gobalisasi sebagai sebuah bentuk structural socioeconomic process dimana sistem modern mendominasi dan memaksa untuk masuk membentuk sebuah kebudayaan dan menciptakan sistemnya sendiri (Kraidy,2005:25-26).
} 
setuju mengenai globalisasi sebagai sebuah kesatuan politik dan ekonomi justru globalisasi menghancurkan identitas nasional (Babran, 2008).

Globalisasi juga dilihat sebagai ancaman invasi budaya yang dapat mengancam nilai tradisi dan budaya. Dalam globalisasi, debat yang paling kontroversial adalah mengenai krisis identitas dan juga pengaruh brand asing dalam memfasilitasi ekspansi globalisasi. Dengan adanya global brand, maka dunia kemudian diekspos dengan kebudayaan lain yang baru dan berbeda dengan yang mereka miliki. Misalnya saja dengan kemunculan Danone Group pada tahun 2007 di Indonesia yang kemudian mengambil alih saham PT Sarihusada Generasi Mahardika Tbk. yang telah berdiri semenjak lepasnya penjajahan di Indonesia. Danone kemudian memasukkan unsur-unsur nilai globalnya dalam perusahaan yang kental dengan nuansa Jawa dan Indonesia karena pada awalnya perusahaan yang berdiri di Yogyakarta ini memang hasil bentukan Unicef dengan Pemerintah Indonesia sendiri. Dengan efisiensi perusahaan, kini perusahaan yang juga produsen susu SGM ini mampu menjadi nomor 1 di segmentasinya dan menguasai $30 \%$ market share di Indonesia (www.sarihusada.co.id).

Imperialisme budaya melihat negara yang lemah sebagai penerima perkembangan globalisasi dan mereka kemudian terjebak dan tidak bisa membela diri fenomena tersebut. Banyak orang melihat globalisasi sebagai bentukan lain dari kebudayaan Amerika, misalnya saja Disneyfication yang juga senada dengan McDonaldisation yang merupakan budaya dari konsumerisme (Kaul, 2011). Disneyfication inilah yang membuat banyak pihak meniru tema Disneyland park yang merupakan sebuah taman hiburan tanpa masalah, sebuah dunia tanpa kenyataan hidup yang sebenarnya. Disneyfication dan McDonaldisation juga menunjukkan trend homogenitas dalam budaya pop western yang merasuk dalam lokalitas masyarakat.

\section{GLOBALISASI SEBAGAI EKSPANSI PASAR}

Globalisasi terbentuk karena kekuatan yang dominan di dunia untuk memenuhi kebutuhan mereka. Dalam perkembangannya, masyarakat kemudian memberikan ideologi baru ini dengan sebutan komunitas internasional (Kaul,2011). Kelompok global expansionist memandang globalisasi sebagai perkembangan yang tidak bisa dihindari sebagai hasil momentum interaksi global dan akan semakin menyusutkan batasan nasional. Menurut Babran (2008) kelompok ini percaya bahwa ekonomi, budaya dan dominasi nasional akan semakin berkurang dalam ekonomi dan budaya global yang semakin homogen.

Bahkan Teori Imperialisme Budaya (cultural imperialism theory) (Jan,2009) yang menyatakan bahwa sistem ekonomi global didominasi oleh negara maju dimana negara dunia ketiga hanya menjadi periferal dalam sistem dengan kontrol yang lemah terhadap perkembangan ekonomi dan politik. Imperialisme budaya merupakan sebuah dominasi budaya dimana negara yang lebih kuat menjajah yang lemah. Efek dari dominasi ini kemudian merefleksikan perilaku dan nilai kebaratan yang kemudian mengarah pada homogenisasi budaya global.

Globalisasi saat ini hanyalah bentuk lain daripada kolonialisme pada jaman dahulu dan merupakan pembunuhan budaya. Brand asing dianggap 'membonceng' globalisasi ini untuk kemudian menginfiltrasi pasar lokal melalui idealisme, pakaian, produk, iklan, film dan musik mendorong lifestyle tertentu. Nilai-nilai hanya sebatas tampilan dan gaya hidup kemudian diterjemahkan dalam pusat perbelanjaan. Orang yang dianggap pahlawan pada masa kini adalah bintang film, bintang iklan, olahragawan atau siapapun yang muncul di siaran televisi. Penonton dicuci otak dan diubah sikap dan cara berbicara, berfikir serta hidup.

Kebanyakan konsumen meyakini bahwa brand dengan kesan global atau asing mampu meningkatkan status penggunanya terutama di kalangan remaja, pekerja bisnis dan pegawai pemerintahan atau pekerjaan lain yang membutuhkan kredibilitas dan autoritas global. Kecenderungan ini kemudian dikenal juga sebagai GCCP (Global Consumer Culture Positioning) (Alden et.al., 1999). Pengunaan endorser juga menjadi bagian GCCP dimana karakteristik endorser dianggap berasosiasi dengan brand sehingga dengan menggunakan endorser akan mampu mengangkat nilai brand itu.

\section{KEMUNCULAN BRAND LOKAL}

Dalam menghadapi arus globalisasi, manifestasi sosial dari identitas selalu dipengaruhi oleh kekuatan dan juga kontribusi dari identitas itu sendiri (Babran, 2008). Sebuah kelompok tidak bisa menutup diri dari brand asing apalagi setelah dibukanya keran pasar bebas atau di Asia dikenal sebagai MEA (Masyarakat Ekonomi Asean) di akhir tahun 2015 nanti. Dengan adanya MEA sebagai pasar tunggal, maka dengan 
mudahnya produk berpindah dari satu negara ke negara lain dan membuat kompetisi pun semakin ketat. Sebuah brand tidak lagi mungkin bisa mempertahankan resistance identity dan berusaha menutup diri dari komunitas. Dalam teorinya, sebuah negara bisa menjaga identitasnya namun hanya dengan mengisolasi diri secara total, menjauhkan diri dari orang lain dan memenuhi kebutuhannya sendiri seperti halnya suku-suku di Afrika dan Amazon. Hal inipun yang coba dipraktekkan oleh Korea Utara dan Kuba namun pada akhirnya tanpa mereka bisa hindari modernitas akan perlahan memasuki budaya mereka.

Di sisi lain, banyak kelompok masyarakat yang membangun posisi bertahan dari dominasi aktor lain. Project identity merupakan pergerakan proaktif yang mendorong kondisi ini. Beberapa negara Asia Timur mengeluarkan statement mengenai 'Asian Values' dimana mereka menggunakan nilai Konfusius yang mencoba menanamkan bahwa komunitas merupakan hal yang paling penting. Asian Values ini yang kemudian mendorong pertumbuhan ekonomi negaranegara di Asia Timur. Asia Timur dianggap mampu menjaga dan merawat tradisinya dalam menghadapi modernitas, kerusakan moral dan juga globalisasi (Moussa, 2013). Misalnya saja tindakan pemerintah China yang menemukan lebih dari 20.000 perusahaan barat dan menekan 2.000 dari mereka untuk mengubah nama produk mereka supaya terdengar lebih dekat dengan China. Hal ini mungkin dilakukan karena pada dasarnya budaya merupakan hak dasar setiap orang dan dalam konteks ini adalah negara hanya saja kemampuan dan keinginan untuk mempertahankanny di tengah perkembangan jaman membutuhkan teknik tersendiri.

Beberapa hal bisa dilakukan oleh brand lokal untuk mempertahankan brand bahkan masuk ke persaingan global pada akhirnya. Pertama, sebuah brand justru harus mendefinisi ulang mengenai identitas mereka dalam era modern sehingga menunjukkan kontrol yang lebih dan mampu menghadapi tantang selanjutnya. Masyarakat tidak bisa tidak peduli pada perubahan namun harus selalui menyesuaikan diri. Beberapa pakar mengatakan bahwa Asian brand akan menemui kesulitan saat mencoba bersaing di taraf global (Babran,2008). Namun hal ini tidak terbukti karena di tengah dunia yang berubah begitu cepat, tidak ada rumus pasti untuk menjadi sukses. Salah satu kasus adalah Sony yang mengklaim produknya yang berbasis kualitas dan inovasi kini kalah saing dengan produk lain berharga murah. Di sisi lain, Samsung dan LG selalu berusaha mengeluarkan tekhnologi baru dengan biaya yang mahal namun mereka berhasil menyingkirkan kompetitornya. Samsung dan LG rupanya mampu melihat peluang di tengah kedinamisan konsumen dan variasi kompetitor (Temporal, 2005).

Kedua, sebuah brand harus mampu membaur dalam pasar global. Beberapa studi sebelumnya mengenai Asianization dari produk barat dengan menekankan kemampuan mereka beradaptasi denga budaya lokal Asia atau pun kemampuannya untuk membaur dalam pasar barat. Produk lokal seharusnya mendalami faktor apa saja yang mampu mendorong kesuksesan mereka, terutama pentingnya menciptakan unique value (Cayla \& Eckhardt,2007). Beberapa brand juga memilih untuk membuat produk yang relatif lebih mahal untuk menunjukkan kesan glamour dan juga kualitas.Tekhnik ini secara sukses dilakukan beberapa brand Asia seperti Giordano, Banyan Tree serta Acer yang mampu menembus pasaran dengan menciptakan brand yang dinamis dan siap menghadapi tantangan pasar global.

Tekhnik yang ketiga, kebanyakan pemilik produk di Asia cenderung hanya memikirkan mengenai bagaimana menciptakan sebuah produk, memberikan nama brand dan memberikan harga setelah ongkos produksi atau yang kemudian dikenal sebagai OEM (Old Economy Model) (Temporal,2005). Hal ini bukan berarti salah, hanya saja tidak sesuai untuk konsumen saat ini dan apabila pemilik produk terus mempertahankan strategi ini bisa jadi produk tersebut cepat ditinggalkan oleh konsumen. Produk harus memikirkan potensi jangka panjang dalam membangun brand. Misalnya Petronas yang telah mencoba menginvestasikan dana di Formula 1 lebih dari 10 tahun lalu dan berambisi untuk menjadi global brand. Saat ini Petronas telah hadir di lebih dari 20 negara dan menduduki posisi ke-75 dalam Fortune Global 500. Hal ini menunjukkan bahwa strategi brand bukanlah program jangka pendek namun membutuhkan waktu yang cukup panjang untuk kemudian membuktikan kesuksesan strategi komunikasinya.

Keempat, sebuah brand harus memperhatikan kualitas produk secara spesifik karena kualitas juga menjadi sorotan tersendiri untuk produk dari Asia sehingga brand harus memastikan bahwa kualitasnya sesuai yang diharapkan konsumen. Hal ini menahan masyarakat global untuk membeli produk dari Asia karena ketidakmampuannya menjaga kualitas produk. Misalnya saja kemudian ada anggapan bahwa semua barang yang memiliki cap 'Made in Vietnam' atau 'Made in Cambodia' memiliki kualitas yang rendah menunjukkan adanya persepsi mengenai kualitas 
yang tidak baik. Hal ini menjadi salah satu pekerjaan yang harus dibenahi oleh pemilik brand yang beridentitas dari negara tersebut.

Kelima, produk harus memberikan servis yang maksimal. Servis juga menjadi kunci penting karena masyarakat Asia dikenal ramah dan peduli terhadap hubungan yang kemudian bisa diwujukan dalam service quality (Temporal, 2005). Salah satu contoh positif adalah Singapore Airlines sebagai brand lokal Singapura yang memiliki taraf internasional. Brand ini diyakini memiliki kekuatan tersendiri dan tergambar dalam LCCP (Local Consumer Culture Positioning) (Alden et.al., 1999) yaitu sebuah strategi yang menghubungkan brand dengan nilai-nilai yang ada di dalam kebudayaan lokal. Bahwa seharusnya sebuah brand mengadaptasi budaya dan identitas masyarakat lokal yang kemudian akan mengonsumsi produk itu sendiri.

\section{HYBRID BRAND MUNCUL SEBAGAI IDENTITAS BARU}

Globalisasi juga memunculkan dilema seperti lokalitas dan global dimana hasilnya bisa menjadi homogenisasi, heterogenisasi, percampuran keduanya atau bahkan tidak sama sekali. Robertson (Koc,2006) menjelaskan mengenai konsep 'glocalization' yang merupakan sebuah interpenetrasi antara lokal dan global dimana global mempengaruhi lokal secara keseluruhan. Di sisi lain, Kraidy (2005:154) menambahkan bahwa bahwa globalisasi, misalnya dalam bentuk glocalization ${ }^{3}$ atau interpenetrasi globalisasi, tidak boleh dilihat sebagai sesuatu yang membahayakan namun justru saling mengisi satu sama lain.

Selain itu fenomena glocalization juga muncul hybrid brand (Cayla \& Eckhardt, 2007) yang berusaha membuat identitas brand tidak nampak dalam brandingnya ${ }^{4}$. Hal ini menunjukkan fenomena baru

\footnotetext{
${ }^{3}$ Glocalization dijelaskan oleh Clifford Geertz (1983) sebagai 'local in itself' yang menyatakan pandangan positif saling mengisi satu sama lain antara lokalitas dan globalisasi. Di sisi lain, pandangan ini mendapatkan tentangan dari Appadurai (1996) bahwa lokalitas itu bukan di dalam diri namun untuk diri sendiri (not only local in itself, but even more important, for itself) sehingga tidak tepat apabila hal ini dianggap sebagai sebuah niat baik.

${ }^{4}$ Konsep hybridity dan heterogeinity budaya lokal telah diperkenalkan oleh Roland Robertson dan Jan Nederveen Pieterse semenjak tahun 1995. Hybriditas sendiri membutuhkan keterlibatan dari paling tidak dua bentuk, gaya atau identitas dua budaya yang cukup berbeda. Hybrid genre sudah banyak bermunculan sejak tahun 1999 bahkan prediksinya telah muncul semenjak tahun 70-an (Kraidy, 2005:6) dan dianggap memiliki keunggulan dalam pasar masa kini.
}

bahwa non-western brand tidak ingin menunjukkan identitas dikarenakan cap buruk yang tidak positif bagi perkembangan brandnya. Misalnya saja brand Haier yang mampu berkompetisi dengan brand asing bahkan masuk ke pasar Amerika dan Eropa karena interpretasi produknya yang dianggap produk global. Haier sangat menjaga imagenya dan berusaha untuk tidak mengaitkan brand dengan asalnya, yaitu China. Hal ini dengan tujuan untuk menjaga persepsi konsumen atas produk keluaran China yang dianggap tidak sebaik keluaran pasaran Eropa, Amerika ataupun Jepang dan Korea (www.internshipchina. com).

Sayangnya saat ini masih banyak orang yang melihat western sebagai pusat dari segala pemikiran sedangkan non-western hanya sebagai bagian pheriperal belaka sehingga hanya dipandang sebelah mata. Namun di sisi lain, brand Asia juga mulai memiliki posisinya dalam pasar global dan regional. Misalnya saja Polygon yang merupakan produk sepeda Indonesia dianggap telah mampu mengidentifikasi konsumen dan pasarnya di pasar regional. Polygon banyak menggunakan nuansa western untuk mengatasi interpretasi negatif tentang negara produsen, yaitu Indonesia, dan menunjukkan kualitas dan prestiges dengan western stamp approval untuk mendukung kesuksesan produknya. Pemilihan logo, iklan, packaging maupun branding lainnya pun dibuat seolah-olah merupakan produk western sehingga sukses melakukan penetrasi pasar global. Bahkan Polygon telah sukses di pasar global sebelum akhirnya memutuskan untuk masuk ke Indonesia.

Di sisi lain, fenomena ini kemudian memunculkan apa yang disebut brands without border (Cayla \& Eckhardt, 2007) dimana simbol dan asosiasi brand tidak merujuk pada budaya tertentu. Adanya pengaruh berbagai budaya kemudian membuat identitas produsen menjadi blur. Brand hybrids ini kemudian menggunakan pendekatan lokal dan global untuk memenangkan hati konsumen. Beberapa brand di Indonesia pada akhirnya memutuskan untuk menggunakan konsep hybrid brand sebagai strategi marketingnya misalnya The Executives, J.Co., Excelso, Terry Palmer dan GT Radial yang pada akhirnya sukses memasuki kompetisi pasar di tingkat regional maupun global.

\section{PENUTUP}

Berkaca pada realitas yang terjadi saat ini, semua negara di bumi ini mengalami proses globalisasi, hanya saja dalam tahapan yang berbeda, ada yang 
lebih cepat dan ada yang lambat, yang disebabkan oleh modernisasi yang terjadi sebelumnya. Globalisasi rasanya sudah niscaya terjadi dan tidak bisa dihindari oleh negara manapun. Kesiapan nasional yang harus dibentuk untuk menghadapi globalisasi dan juga mempertahankan identitas budaya.

Walaupun kemudian globalisasi dilihat sebagai ancaman dan bagian dari invasi ekonomi dan budaya, namun pada dasarnya hal ini tidak bisa dihindari. Justru masyarakat yang harus bersiap diri untuk menerima pengaruh globalisasi ini secara nyata dalam kehidupan mereka. Ketika mereka melihat masyarakat sebagai bagian dari global consumer, kemudian akan dengan mudah mereka memetakannya berdasarkan aspek psikologis, bukan lagi demografis.

Tentu pada prakteknya, pengonsepan akan global consumer tidak akan semudah itu karena ada banyak masyarakat yang kemudian menjadi inisiator project identity untuk kemudian menonjolkan nilai dari identitas budaya yang dimilikinya dan kemudian menjadi nilai tambah bagi brand. Hal ini secara cerdik dilihat oleh beberapa brand dan menjadi nilai jual tersendiri.

Untuk kemudian bisa sukses di kompetisi global, setiap brand harus memahami identitas mereka sendiri dan apa yang ingin mereka raih, mereka juga harus memiliki unique value yang membedakan mereka dengan brand lainnya. Hal ini menjadi kata kunci karena ketika sebuah produk dianggap memiliki kepribadian, maka akan lebih mudah bagi produk itu sendiri untuk mengidentifikasi target marketnya dan kemudian mencapai target yang diinginkannya.

Hybrid brand menjadi sebuah fenomena tersendiri di tengah konflik globalisasi dan lokalisasi, namun pada dasarnya strategi brand saat ini telah menemukan titik evolusinya untuk bertahan. Bahwa untuk bertahan hidup, sebuah brand bisa saja memilih mati, mati suri ataupun mengganti identitasnya untuk kemudian pada akhirnya mampu mencapai objektif produknya. Ke depannya, akan sangat menarik apabila peneliti mendalami penyusunan strategi hybrid brand serta pengukuran efektivitas brandingnya di mata konsumen.

\section{DAFTAR PUSTAKA}

Alden, D. L., Steenkamp, J. B. E. M., \& Batra, R. 1999. Brand Positioning Through Advertising in Asia, North America, and Europe: The Role of Global Consumer Culture. Journal of Marketing, 63(1), 75-87.
Ardhiati, M. Y. 2016. Akuisisi Lazada, Alibaba Jadi Raja E-Commerce di Asia Tenggara. Katadata (online). Terarsip dalam: http://katadata.co.id/ berita/2016/04/12/akuisisi-lazada-alibaba-jadiraja-ecommerce-di-asia-tenggara.

Babran, S. 2008. Media, globalization of culture and identity crisis in developing countries. Intercultural Communication Studies, 17(2), 212221.

Cayla, J. \& Eckhardt, G. M. 2007. Asian brands without borders: regional opportunities and

Challenges. International Marketing Review, 24(4), 444-456.

Embong, A. R. 2011. The question of culture, identity and globalization: an unending debate 1. Kajian Malaysia, 29(1), 11-22.

Hall, S. 1991. The local and the global: globalization and ethnicities. In A.D. Kind (ed.) Culture, Globalization and the World System. London: Macmillan.

Jan, M. 2009. Globalization of Media: Key Issues and Dimensions. European Journal of Scientific Research, 29(1), 66-75.

Kaul, V. 2011. Globalisation and Media. Mass Communication and Journalism, 1(1). Terarsip dalam: http://dx.doi.org/10.4172/2165-7912. 1000105

Kaul, V. 2012. Globalisation and crisis of cultural identity. Journal of Research in International Business and Management, 2(13), 341-349.

Koc, M. 2006. Cultural identity crisis in the age of globalization and technology. The Turkish Online Journal of Educational Technology, 5(1), 37-43.

KPMG International. 2015. MNCs in Southeast Asia. Singapore: KPMG International Cooperative.

Kraidy, M. M. 2005. Hybridity, or the Cultural Logic of Globalization. Philadelphia: Temple University Press.

Moussa, S. 2013. Culture and globalization. Globalization101. Terarsip dalam: http://www.globalization101.org

Rantanen, Terhi. 2005. The Media and Globalization. London: Sage Publication.

Robertson, R. 1992. Globalization: Social Theory and Global Culture. London: Sage.

Temporal, P. 2005. Branding for survival in Asia. Brand Management, 12(5), 374-378. Singapore: Henry Stewart Publications.

Turner, B.S. and Khondker, H.H. 2010. Globalization: East and West. London: Sage Publication. 